\title{
Pengaruh Pendidikan, Pelatihan dan Kedisiplinan terhadap Kinerja Pegawai pada Kantor KPP Setiabudi Jakarta Selatan
}

\author{
Andri Gunawan \\ Sekolah Tinggi Ilmu Ekonomi Muhammadiyah Jakarta
}

\begin{abstract}
Abstrak
Penelitian ini bertujuan untuk mengetahui pengaruh pendidikan, pelatihan dan kedisiplinanterhadap kinerja pegawai. Data yang dipergunakan adalah data primer yang diper- oleh dari penyebaran kuesioner kepada 50 orang pegawai dilingkungan kantor KPP Setiabudi Jakarta Selatan. Metoda yang digunakan untuk menganalisis hubungan dan pengaruhnya adalah metoda analisis korelasi berganda, uji hipotesa $\mathrm{F}$ dan $\mathrm{t}$ dengan menggunakan bantuan program SPSS Versi 16. Hasil analisis diperoleh koefisien korelasi keseluruhan variabel bebas terhadap variabel terikat yang dinyatakan berkorelasi positif dan sangat kuat yang ditunjukkan dari nilai $\mathrm{R}$ sebesar 0,988 hampir mendekati 1, dan nilai $\mathrm{R}$ square nya sebesar 0,977. Artinya 97,7\% seluruh variabel bebas yakni: pendidikan, pelatihan dan disiplin sangat berpengaruh terhadap kinerja pegawai. Sedangkan koefisien korelasi parsial dari setiap variabel bebas, menghasilkan persamaan: $\mathrm{Y}=$ $2,673+0,148 \mathrm{X} 1+1.083 \mathrm{X} 2+0,291 \mathrm{X} 3+\varepsilon$. Hasil uji hipotesis, menunjukkan bahwa nilai thitung untuk b1 $=2,658, \mathrm{~b} 2=11,592$ dan $\mathrm{b} 3=6,185$ dan ttabel $=1,67793$. Karena thitung untuk b1 $>$ ttabel yakni $\mathrm{b} 1=2,658$ $>1,67793$, maka terdapat hubungan yang erat antara pendidikan dengan kinerja pegawai. Selanjutnya thitung untuk b2 >ttabel, yakni b2 = 11,592 > 1,67793, maka terdapat hubungan yang erat antara pelatihan dengan kinerja pegawai. Demikian pula dengan thitung untuk b3 >ttabel, yakni b3 =6,185 > 1,67793, maka terdapat hubungan yang erat antara disiplin dengan kinerja pegawai. Sedangkan hasil uji F, diperoleh Fhitung = 652,038 dan Ftabel = 3,20. Karena Fhitung > Ftabel yakni 652,038 > 3,20, maka seluruh variabel bebas berhubungan erat dengan variabel terikat, atau dengan kata lain pendidikan, pelatihan dan disiplin bersamasama berhubungan secara signifikan dengan kinerja pegawai.
\end{abstract}

Kata Kunci: Pendidikan, Pelatihan, kedisiplinan dan Kinerja Pegawai.

\section{PENDAHULUAN}

Pegawai negeri sebagai aparatur negara dituntut memberi palayanan yang baik kepada masyarakat, untuk mempertahankan kelang- sungan hidup suatu instansi perlu didukung oleh sumber daya manusia yang mempunyai jiwa kepemimpinan, memiliki keterampilan, memiliki kreativitas yang tinggi. Kualitas kerja pegawai negeri sipil (PNS) dipandang kurang memadai dan berada di bawah standar kualitas yang diharapkan.seperti lambatnya pemberian pelayanan kepada masyarakat umum, kurang terkoordinasinya beberapa pekerjaan, kurang menghargai jam kerja, disiplin dan waktu kerja yang semuanya mengindikasikan bahwa kualitas pegawai negeri sipil (PNS) perlu dibenahi. Sumber daya manusia yang berkualitas, bermotivasi tinggi dan mau bekerja sama dalam team akan menjadi kunci keberhasialan organisasi. Karena itu pimpinan harus dapat menetapkan sasaran kerja yang akan menghasilkan pegawai yang berkualitas tinggi, bermotivasi tinggi dan produktif. Penetapan target-target spesifik dalam kurun waktu tertentu tidak hanya bersifat kuantitatif tetapi juga bersifat kualitatif misalnya, dengan pengembangan diri untuk menguasai pengetahuan dan keahlian yang diperlukan untuk pekerjaan dengan tingkat kompetensi yang makin baik.

Di dalam penilaian kinerja harus benar- benar obyektif yaitu dengan mengukur kinerja pegawai yang sesungguhnya atau mengeva- luasi perilaku yang mencerminkan keberha- silan pelaksanaan pekerjaan. Penilaian kinerja yang obyektif akan memberikan feedback yang tepat terhadap perubahan perilaku ke arah peningkatan produktivitas kinerja yang diharapkan. (Hariandja: 2002:85). Menurut Armstrong (1998:32) penilaian kinerja dida- sarkan pada pengertianknowledge, Skill, ex- pertise, dan behavior yaitu diperlukan 
seseorang untuk mengerjakan pekerjaan dengan baik dan analisa lebih luas terhadap attributes dan perilaku individu. Untuk melihat kinerja pegawai diperlukan faktor-faktor yang dapat mempengaruhinya.

\section{Perumusan Masalah}

a. Apakah pendidikan memberikan pengaruh yang signifikan terhadap kinerja pegawai KPP Setiabudi Jakarta Selatan?

b. Apakah pelatihan memberikan pengaruh yang signifikan terhadap kinerja pegawai KPP Setiabudi Jakarta Selatan?

c. Apakah disiplin memberikan pengaruh yang signifikan terhadap kinerja pegawai KPP Setiabudi Jakarta Selatan?

d. Apakah pendidikan, pelatihan, dan disiplin bersama-sama meberikanpengaruhyang signifikan terhadap kinerja pegawai KPP Setiabudi Jakarta Selatan?

\section{Tujuan Penelitian}

a. Untuk mengetahui besarnya pengaruh pendidikan terhadap kinerja pegawai KPP Setiabudi Jakarta Selatan?

b. Untuk mengetahui besarnya pengaruh pelatihan terhadap kinerja pegawai KPP Setiabudi Jakarta Selatan?

c. Untuk mengetahui besarnya pengaruh disiplin terhadap kinerja pegawai KPP Setiabudi Jakarta Selatan?

d. Untuk mengetahui besarnya pengaruh pendidikan, pelatihan, dan disiplinterhadap kinerja pegawai KPP Setiabudi Jakarta Selatan?

\section{KAJIAN LITERATUR}

\section{Pendidikan}

Menurut Zainun (1996:62) Pendidikan pada dasarnya dimaksudkan untuk memper- siapkan sumber daya manusia sebelum me- masuki pasar kerja. Pendidikan mempunyai fungsi sebagai penggerak sekaligus pemacu terhadap potensi kemampuan sumber daya manusia dalam meningkatkan prestasi kerjanya (Irianto 2003:93). Menurut Hama- lik (2000:57). Pendidikan merupakan upaya untuk mengembangkan sumber daya manu- sia, terutama untuk mengembangkan kemampuan intelektual dan kepribadian. Sedangkan menurut Irianto (2003:92) dalam pengembangan sumber daya manusia (human resource developpment) bahwa ni- lai-nilai kompetensi seseorang pekerja dapat dipupuk melalui program pendidikan, pe- ngembangan atau pelatihan yang berorien- tasi pada tuntutan kerja aktual dengan pene- kanan pada pengembangan skill, knowledge dan ability yang secara signifikan akan da- pat memberi standar perilaku dalam sistem dan proses kerja yang diterapkan. Melalui Pendidikan seseorang dipersiapkan untuk memiliki bekal agar siap tahu, mengenal dan mengembangkan metode berpikir secara sistematik agar dapat memecahkan masalah yang akan dihadapi dalam kehidupan dike- mudian hari (Sedarmayanti, 2001:53). Me- nurut instruksi Presiden No. 15 tahun 1974, "Pendidikan adalah segala usaha untuk membina kepribadian dan mengembangkan kemampuan manusia Indonesia, jasmani dan rohaniah, yang berlangsung seumur hidup, baik didalam maupun diluar sekolah, dalam rangka pembangunan persatuan Indonesia dan masyarakat adil dan makmur berda- sarkan Pancasila". Sedangkan pengertian pendidikan sesuai dengan Undang-Undang Republik Indonesia No. 2 tahun 1989 tentang sistem Pendidikan Nasional disebut bahwa: "Pendidikan adalah usaha sadar untuk menyiapkan peserta didik melalui kegiatan bimbingan, pengajaran dan latihan bagi peranannya dimasa yang akan datang".

\section{Pelatihan}

Menurut Bernardin and Russell dalam Gomes (2000:37) pelatihan adalah setiap usaha untuk memperbaiki performance pekerja pada pekerjaan tertentu yang sedang menjadi tanggung jawabnya, atau satu pekerjaan yang 
ada kaitannya dengan pekerjaannya. Pelatihan merupakan cara terpadu yang diorientasikan pada tuntutan kerja aktual, dengan penekanan pada pengembangan skill, knowledge, dan ability, (Mangkunegara, 2000:82). Menurut Yoder (1962:39) membedakan antara istilah Pe- latihan (training) dan pengembangan (development), dimana Pelatihan ditujukan untuk pegawai pelaksana dan pengawas. Sedangkan pengembangan ditu- jukan untuk pegawai tingkat manajemen. Sementara Umar (2000:92) pelatihan (training) ditujukan pada kebutuhan saat ini untuk dapat menguasai berbagai keterampilan dan teknik pelaksanaan kerja, sedangkan pengembangan bertujuan untuk menyiapkan pegawai agar siap memangku jabatan dimasa yang akan datang. Kenneth dan Robinson (1998:48) mendefinisikan pendidikan dan pelatihan sebagai proses ke- giatan pembelajaran antara pengalaman untuk mengembangkan pola perilaku seseorang dalam bidang pengetahuan, keterampilan atau sikap untuk mencapai standar yang diharapkan. Menurut Lembaga Administrasi Negara (LAN) "Pendidikan dan pelatihan adalah penyelenggaraan proses belajar mengajar dalam rangka meningkatkan kemampuan pegawai negeri sipil dalam melaksanakan jabatannya".

Dari berbagai definisi tersebut di atas, maka tujuan Pendidikan dan Pelatihan adalah:
a. meningkatkan pengetahuan baik teknis maupun manajemen.
b. meningkatkan keterampilan.
c. meningkatkan sikap maupun perilaku yang bertanggungjawab.
d. meningkatkan produktifitas. Dan
e. mencapai sasaran dan tujuan organisasi yang semaksimal mungkin.

\section{Disiplin}

Secara etiomologis kata disiplin berasal dari kata Latin "diciplina" yang berarti latihan atau pendidikan kesopanan dan kerohanian serta pengembangan tabiat (Moekijat,1984:63). Menurut Nitisemito (1988:25) terdapat beberapa faktor yang mempengaruhi timbulnya perilaku disiplin kerja, yaitu: tujuan pekerjaan, kemampuan pekerjaan, teladan pimimpin, kesejahteraan, keadilan, pengawasan melekat (waskat), sanksi hukum, ketegasan, dan hubungan kemanusiaan. Menurut Commings (1984:76) pembentukan perilaku disiplin kerja dapat dilakukan melalui dua cara yaitu: (1) Preventive dicipline yaitu merupakan tindakan yang diambil untuk mendorong para pekerja mengikuti atau mematuhi norma-norma dan aturan-aturan sehingga pelanggaran tidak terjadi. Tujuannya adalah untuk mempertinggi kesadaran pekerja tentang kebijaksanan dan peraturan pengalaman kerjanya. (2) Corrective Dicipline yaitu merupakan suatu tindakan yang mengikuti pelanggaran dari aturan-aturan, hal tersebut mencoba untuk mengecilkan pelanggaran lebih lanjut sehingga diharapkan untuk prilaku dimasa mendatang dapat mematuhi norma-norma yang baik.

Gibson (1988:56) mengemukakan ada beberapa tindakan karyawan sehingga dapat dihukum adalah keabsenan, kelambanan, meninggalkan tempat kerja, mencuri, tidur ketika bekerja, berkelahi, mengancam pimpinan, mengulangi prestasi buruk, melanggar aturan, dan pembangkangan perintah, memperlakukan pelanggaran secara tidak wajar, memperlambat pekerjaan, menolak kerja sama dengan rekan, menolak kerja lembur, memiliki dan menggunakan obat-obatan ketika bekerja, merusak peralatan, menggunakan bahasa atau kata-kata kotor, pemogokan secara ilegal.

\section{Kinerja Pegawai}

Performance adalah hasil kerja yang dapat dicapai oleh seseorang atau sekelompok orang dalam suatu organisasi, sesuai dengan tanggung jawab masing-masing, dalam rangka upaya mencapai tujuan organisasi bersang- kutan secara legal, tidak melanggar hukum dan sesuai dengan moral maupun etika (Prawirosentono, 1999:51). Menurut Sima- mora (1995:42) kinerja yaitu merupakan suatu pencapaian persyaratan pekerjaan tertentu yang akhirnya secara nyata dapat tercermin keluaran yang dihasilkan.Suprihanto (2000:34) menyebutkan kinerja yaitu hasil kerja seseorang selama periode tertentu diban- dingkan dengan berbagai kemungkinan, mi- salnya standar, target/sasaran.Menurut Mang- kunegara (2001:94) kinerja berasal dari kata Job Performance atau Actual Performance (prestasi kerja atau prestasi sesungguhnya yang dicapai oleh 
seseorang). Kinerja kar- yawan merefleksikan bagaimana karyawan memenuhi keperluan pekerjaan dengan baik. (Rue dan Byars, 1995:37). Kinerja seorang karyawan akan baik bila ia mempunyai keahlian (skill) yang tinggi, bersedia bekerja karena gaji atau diberi upah sesuai dengan perjanjian dan mempunyai harapan (expectation) masa depan lebih baik. (Prawiro- sentono, 1999:64). Hariandja (2002:52) me- nyatakan bahwa tujuan penilaian kinerja untuk memberikan feedback kepada pegawai dalam upaya memperbaiki tampilan organisasi, dan secara khusus dilakukan dalam kaitannya dengan berbagai kebijaksanaan terhadap pegawai seperti untuk tujuan promosi, kenaikan gaji, pendidikan, dan pelatihan.

\section{Hipotesis Penelitian}

\section{Hipotesis 1:}

H01: Diduga bahwa pendidikan tidak mem- berikan pengaruh yang signifikan terhadap kinerja pegawai KPP Setiabudi Jakarta Selatan?

Ha1: Diduga bahwa pendidikan memberikan pengaruh yang signifikan terhadap kinerja pegawai KPP Setiabudi Jakarta Selatan?

\section{Hipotesis 2:}

H02: Diduga bahwa pelatihan tidak mem- berikan pengaruh yang signifikan terhadap kinerja pegawai KPP Setiabudi Jakarta Selatan?

Ha2: Diduga bahwa pelatihan memberikan pengaruh yang signifikan terhadap kinerja pegawai KPP Setiabudi Jakarta Selatan?

\section{Hipotesis 3:}

H03: Diduga bahwa disiplin tidak mem- berikan pengaruh yang signifikan terhadap kinerja pegawai KPP Setiabudi Jakarta Selatan?

Ha3: Diduga bahwa disiplin memberikan pengaruh yang signifikan terhadap kinerja pegawai KPP Setiabudi Jakarta Selatan?

\section{Hipotesis 4:}

H04: Diduga bahwa pendidikan, pelatihan, dan disiplin tidak memberikan pengaruh yang signifikan terhadap kinerja pegawai KPP Setiabudi Jakarta Selatan?

Ha4: Diduga bahwa pendidikan, pelatihan, dan disiplin memberikan pengaruh yang signifikan terhadap kinerja pegawai KPP Setiabudi Jakarta Selatan?

\section{METODE}

Metode yang digunakan dalam pe- nelitian ini adalah metode deskriptif kualitatif dan kuantitatif yang menguraikan suatu kegejala atau fenomena secara berurutan serta memberikan gambaran yang jelas terhadap gejala atau fenomena yang mempengaruhinya.

\section{Teknik Pengumpulan Data}

Data yang dipergunakan dalam penelitian ini adalah data primer yang dikumpulkan melalui penyebaran kuesioner kepada pegawai yang ada di KPP Setiabudi Jakarta Selatan.

\section{Populasi dan Sampel}

Populasi yang menjadi sasaran observasi adalah pegawai yang bekerja dilingkungan KPP Setiabudi Jakarta Selatan yang berjumlah 58 orang. Sedangkan besarnya sampel dihitung dengan menggunakan rumusan berikut (Supranto, 2001):

$$
n=\frac{\mathrm{N}}{\mathrm{N} . \mathrm{d} 2+1}
$$

dimana: 


$$
\begin{aligned}
& \mathrm{n}=\text { ukuran sampel } \\
& \mathrm{N}=\text { ukuran populasi } \\
& \mathrm{d}=\text { galat pendugaan }
\end{aligned}
$$

Dengan demikian, jumlah sampel yang diambil adalah

$$
n=\frac{58}{-------5}=50 \text { responden }
$$

58. $0.05^{2}+1$

\section{Teknik Analisis Data Uji Validitas}

Uji validitas adalah untuk mengetahui tingkat kevalidan dari instrumen (kuesioner) yang digunakan. Adapun perhitungan korelasi productmoment dengan rumus yang dikemukakan oleh Arikunto (1998:82):

$$
\mathrm{r} \frac{\mathrm{n} \sum \mathrm{XY}-\left(\sum \mathrm{X}\right)\left(\sum \mathrm{Y}\right)}{\sqrt{\left.\left[\mathrm{N} \sum \mathrm{X}^{2}-\left(\sum \mathrm{X}\right)^{2}\right] \mathrm{N} \sum \mathrm{Y}^{2}-\left(\sum \mathrm{Y}\right)^{2}\right]}}
$$

\section{Dimana: \\ $\mathrm{r}=$ Koefisien korelasi $\mathrm{n}=$ Banyaknya sampel $\mathrm{X}=$ Skor tiap item \\ $\mathrm{Y}=$ Skor total variabel}

\section{Uji Reliabilitas}

Uji reliabilitas dimaksudkan untuk menge- tahui adanya keabsahan masing-masing butir, rumus yang digunakan sebagai berikut:

$$
\sigma=\underline{\square N \quad N}
$$

$$
\begin{aligned}
& \mathrm{r} 11=\text { reliabilitas instrumen } \\
& \mathrm{k} \quad=\text { banyaknya butir pertanyan } \\
& \square \mathrm{b} 2 \quad=\text { jumlah varians butir } \\
& \square \mathrm{t} 2=\text { jumlah varians total }
\end{aligned}
$$

\section{Model Regresi Berganda}

Untuk menganalisa besarnya hubungan dan pengaruh variabel bebas terhadap variabel terikat seperti berikut ini:

$\mathrm{Y}=\mathrm{a}+\mathrm{b} 1 \mathrm{X} 1+\mathrm{b} 2 \mathrm{X} 2+\mathrm{e}$

\section{Koefisien determinasi (R2)}

Untuk mengetahui kesesuaian atau ketepatan hubungan antara variabel independent dan variabel dependent dalam suatu persamaan regresi.rumusan yang digunakan yaitu:

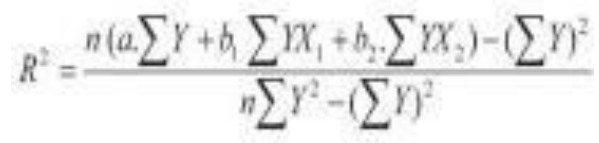


Nilai R2 akan berkisar antara 0 sampai 1 . Apabila nilai $\mathrm{R} 2=1$ menunjukkan bahwa variabel bebas baik X1 maupun X2, mampu menerangkan variabel Y sebesar 100\%. Sebaliknya, apabila R2 $=0$, maka variabel X1 maupun $\mathrm{X} 2$ tidak dapat menerangkan variabel $\mathrm{Y}$

\section{HASIL DAN PEMBAHASAN}

\section{ANALISA DATA}

\section{Uji Multikolinieritas}

Uji multikolinieritas variabel X1 (pendidikan), X2 (pelatihan), X3 (disiplin) dan Y (kinerja pegawai) dilakukan dengan melihat nilai VIF nya, sebagaimana yang diperlihatkan pada tabulasi berikut ini.

\section{Coefficients $^{\mathrm{a}}$}

\begin{tabular}{|c|c|c|c|c|c|c|c|c|}
\hline & \multirow{2}{*}{ Model } & \multicolumn{2}{|c|}{$\begin{array}{c}\text { Unstandardized } \\
\text { Coefficients }\end{array}$} & \multirow{2}{*}{$\begin{array}{c}\text { Standardiz } \\
\text { Coefficien }\end{array}$} & \multirow{2}{*}{$\mathrm{T}$} & \multirow{2}{*}{ Sig. } & \multicolumn{2}{|c|}{$\begin{array}{c}\text { Collinearity } \\
\text { Statistics }\end{array}$} \\
\hline & & B & $\begin{array}{l}\text { Std. } \\
\text { Error }\end{array}$ & & & & Tolerance & VIF \\
\hline \multirow[t]{4}{*}{1} & (Constant) & 2.673 & .748 & & 3.573 & .001 & & \\
\hline & Pendidikan & .148 & .056 & .085 & 2.658 & .011 & .483 & 2.069 \\
\hline & Pelatihan & 1.083 & .093 & .622 & 11.592 & .000 & .174 & 5.762 \\
\hline & Disiplin & .291 & .047 & .325 & 6.185 & .000 & .181 & 5.516 \\
\hline
\end{tabular}

a. Dependent Variable: Kinerja

\section{Sumber : Data diolah}

Dari tabulasi di atas terlihat bahwa nilai tolerance dari variabel pendidikan, pelatihan, disiplin, dan kinerja menunjukan dibawah $10 \%$, atau Variance Inflation Factor nya tidak ada yang melebihi dari 10. Variabel pendidikan dengan tolerance sebesar $0,483(\mathrm{VIF}=2,069)$, pelatihan dengan tolerance sebesar $0,174(\mathrm{VIF}=$ 5,762), disiplin dengan tolerance sebesar $0,181(\mathrm{VIF}=5,516$, maka dapat dikatakan bahwa model regresi dari ketiga variabel tersebut dapat dikatakan tidak ada masalah multikolinearitas. (Gujarati, 2003:53).

\section{Uji Heteroskedastisitias}

Uji heterokedastisitas seluruh variable, dilakukan dengan melihat grafik (scatter plot) berikut ini.

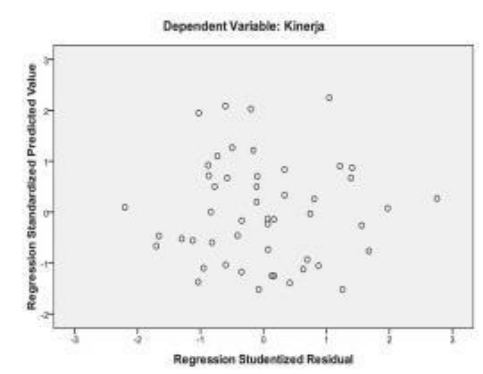

\section{Gambar 1.}

Uji Heteroskedastisitas

Dari hasil uji scatter plot di atas, telihat bahwa titik-titik menyebar dan tidak mem- bentuk pola lingkaran, garis, kerucut, sehingga dapat dikatakan bahwamodel regresi tersebut tidak ada masalah dengan heterokdesitas. 


\section{Uji Autokolerasi}

Uji autokorelasi seluruh variabel yang dilakukan dengan melihat hasil Durbin Watson, ditunjukan pada tabulasi berikut ini.

\begin{tabular}{l|c|r|r|r|r|}
\hline Model & $\mathrm{R}$ & R Square & $\begin{array}{c}\text { Adjusted R } \\
\text { Square }\end{array}$ & $\begin{array}{c}\text { Std. Error of } \\
\text { the Estimate }\end{array}$ & $\begin{array}{c}\text { Durbin- } \\
\text { Watson }\end{array}$ \\
\hline 1 & .988 & .977 & .976 & 1.571 & $\mathbf{2 . 1 6 4}$ \\
\hline
\end{tabular}
a. Predictors: (Constant), Disiplin, Pendidikan, Pelatihan

\section{Uji Normalitas}

Uji normalitas bertujuan untuk menguji apakah data yang terdapat di dalam setiap variabel berdistribusi secara normal atau tidak. Hasil uji normalitas variable sebagaiman yang ditunjukkan pada gambar 2. Dari grafik di atas terlihat bahwa titik- titik berada disekitar garis diagonal, sehingga dapat dikatakan bahwa seluruh data terdistribusi secara normal.

Model Summary
\begin{tabular}{|l|c|r|r|r|r|}
\hline Model & R & R Square & $\begin{array}{l}\text { Adjusted } \\
\text { R Square }\end{array}$ & $\begin{array}{l}\text { Std. Error of } \\
\text { the Estimate }\end{array}$ & $\begin{array}{l}\text { Durbin- } \\
\text { Watson }\end{array}$ \\
\hline 1 & .988 & .977 & .976 & 1.571 & 2.164 \\
\hline
\end{tabular}

Gambar 2. Uji Normalitas

\section{Koefisien Determinasi}

Dari tabulasi di atas terlihat bahwa koefisien korelasi variabel bebas terhadap variabel terikat yang dinyatakan berkorelasi positif dan sangat kuat yang ditunjukkan dari nilai $\mathrm{R}$ sebesar 0,988 hampir mendekati 1, dan nilai $\mathrm{R}$ square nya sebesar 0,977. Artinya 97,7\% seluruh variabel bebas yakni: pendidikan, pelatihan, dan disiplin sangat berpengaruh terhadap kinerja pegawai. Sedangkan sisanya 3,3\% disebabkan oleh faktor lainnya diluar pengamatan.

\section{Regresi Berganda}

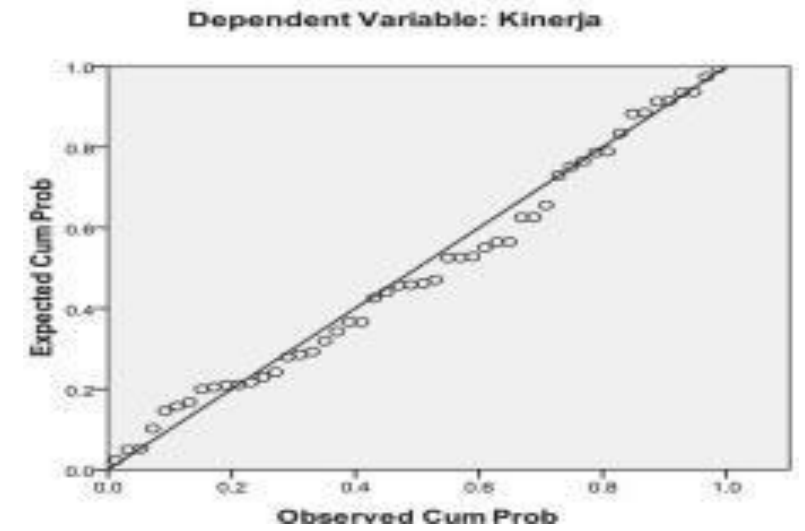

Dari tabulasi di atas, diperoleh koefisien korelasi parsial dari setiap variabel bebas dengan tingkat signifikansi, sehingga persamaan regresi berganda yang menunjukkan hubungan pendidikan, pelatihan, dan disiplin terhadap kinerja pegawai dapat dituliskan sebagai berikut. $\mathrm{Y}=2,673+0,148 \mathrm{X} 1+1,083 \mathrm{X} 2+0,291 \mathrm{X} 3+\varepsilon$

Dimana:

$\mathrm{Y}=$ Kinerja pegawai 


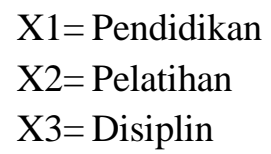

Dari persamaan tersebut dapat diinterpretasikan bahwa, jika pendidikan pegawai ditambah atau naik 1\%, maka kinerja pegawai akan naik sebesar $0,148 \%$. Demikian pula, jika pegawai diberi pelatihan, dan disiplin dalam melaksanakan tugas-tugasnya tentu memberikan kontribusi terhadap peningkatan kinerja pegawai sebesar $1,083 \%$.

Coefficients $^{\mathrm{a}}$

\begin{tabular}{|c|c|c|c|c|c|c|c|c|}
\hline & \multirow{2}{*}{ Model } & \multicolumn{2}{|c|}{$\begin{array}{l}\text { Unstandardized } \\
\text { Coefficients }\end{array}$} & \multirow{2}{*}{$\begin{array}{c}\text { Standardiz } \\
\text { Coefficien } \\
\text { Beta }\end{array}$} & \multirow{2}{*}{$\mathrm{T}$} & \multirow{2}{*}{ Sig. } & \multicolumn{2}{|c|}{$\begin{array}{l}\text { Collinearity } \\
\text { Statistics }\end{array}$} \\
\hline & & B & $\begin{array}{l}\text { Std. } \\
\text { Error }\end{array}$ & & & & Tolerance & VIF \\
\hline \multirow[t]{4}{*}{1} & (Constant) & 2.673 & .748 & & 3.573 & .001 & & \\
\hline & Pendidikan & .148 & .056 & .085 & 2.658 & .011 & .483 & 2.069 \\
\hline & Pelatihan & 1.083 & .093 & .622 & 11.592 & .000 & .174 & 5.762 \\
\hline & Disiplin & .291 & .047 & .325 & 6.185 & .000 & .181 & 5.516 \\
\hline
\end{tabular}

a. Dependent Variable: Kinerja

\section{PENUTUP}

\section{Simpulan}

Koefisien korelasi seluruhan variabel bebas terhadap variabel terikat yang dinyatakan berkorelasi positif dan sangat kuat yang ditunjukkan dari nilai $\mathrm{R}$ sebesar 0,988 dan nilai $\mathrm{R}$ square nya sebesar 0,977 . Artinya $97,7 \%$ seluruh variabel bebas yakni:pendidikan, pelatihan dan disiplin sangat berpengaruh terhadap kinerja pegawai. Sedangkan sisanya 3,3\% tidak diamati dalam penelitian ini.. Hal ini menjadi sangat logis, karena bagaimana mungkin seorang pegawai dapat mengerjakan tugas-tugasnya dengan baik dan berhasil guna bilamana yang bersangkutan tidak memiliki pengetahuan, keterampilan dan disiplin dalam bekerja.

Hasil uji hipotesis secara parsial (uji t), menunjukkan bahwa nilai thitung untuk b1 $=2,658$, b2 $=11,592$ dan $\mathrm{b} 3=6,185$. Untuk menentukan nilai ttabel adalah derajat bebasnya $=n-k=50-3=47$, tingkat signifikansi $=$ $5 \%$, maka nilai ttabel diperoleh dari tabel adalah 1,67793. Karena thitung untuk b1 > ttabel yakni b1 $=2,658>$ 1,67793 ini berarti Hal diterima, Hal ini menunjukkan bahwa terdapat hubungan yang erat antara pendidikan dengan kinerja pegawai. Selanjutnya, thitung untuk b2 >ttabel, yakni b2 $=11,592>1,67793$ ini berarti Ha2 diterima. Hal ini dinyatakan bahwa terdapat hubungan yang erat antara pelatihan dengan kinerja pegawai.Demikian pula halnya dengan thitung untuk b3 >ttabel, yakni b3 $=6,185>1,67793$ ini berartiHa3 diterima. Hal ini menunjukkan bahwa terdapat hubungan yang erat antara disiplindengan kinerja pegawai. Sedangkan hasil uji F, diperoleh Fhitung $=652,038$ dan untuk menentukan Ftabel derajat kebebasannya adalah $=\mathrm{n}-\mathrm{k}=50-3=47$, derajat pembilang $\mathrm{k}-1=3-1=2$, tingkat signifikansi $=5 \%$, maka diperoleh Ftabel dari tabulasi statistika $=3,20$. Karena Fhitung $>$ Ftabel yakni $652,038>3,20$ ini bearti Ha, diterima. Hal ini dinyatakan bahwa seluruh variabel bebas berhubungan erat dengan variabel terikat, atau dengan kata lain pendidikan,pelatihan dan disiplin secara bersama-sama berhubungan dengan kinerja pegawai. 


\section{Saran}

a. perlu mempertahankan kinerja para pegawainya melalui peningkatan stratifikasi pendidikannya maupun ketrampilannya melalui program-program pelatihan yang menunjang pelaksanaan tugas sehari-hari.

b. Demikian pula dengan kedisiplinan para pegawai untuk terus dibina dan diberikan penghargaan kepada para pegawai yang disiplin dan berkinerja baik.

\section{DAFTAR PUSTAKA}

Bernardin, H. John and Russel, E. A. 2000.Human resource Management, An Experiential Approach. Mc. Graw Hill International Edition, Singapore: Mac Graw Hill Book Co.

Gibson. 1998. Human Resources Management. The Fast Think MBA Series (Terjemahan).Jakarta: PT. Elex Media Komputindo.

Gujarati, Damodar N. 2003. Basic Econometrics. 4th edition.New York: Mc Graw - Hill International.

Hamalik, 2000.Model-model Pengembangan Kurikulum.PT. Citra Aditya. Bakti, Bandung

Irianto, Yusuf. 2003. Tema-Tema Pokok Manajemen Sumber Daya Manusia. Surabaya: Insan Cendikia

Instruksi Presiden No. 15 tahun 1974 tentang Pendidikan

Kenneth and Robins. 1998. Performance Management. Edisi Bahasa Indonesia. Jakarta: Sun.

Mangkunegara, Anwar Prabu. 2000.Manajemen Sumber Daya Manusia. Bandung: PT. Remaja Rosda Karya.

Moekijat.1884. Manajemen Tenaga Kerja dan Hubungan Kerja.Cetakan ke III. Bandung: Pionir Jaya.

Marihot Tua Efendi Hariandja, 2002. Manajemen Sumber Daya Manusia, Jakarta PT. Gramedia Widiasaran Indonesia.

Prawirasentono, S 1999.Analisis Kinerja Organisasi, PT. Rineka, Cipta, Bandung

Rue and Byars, 1995.Manajemen Sumber Daya Manusia. Jakarta: Salemba Empat.

Suprihanto, J. 2000. Statistika Teori dan Aplikasi, Jilid 2. Jakarta. Erlangga.

Sedarmayanti. 2001. "Sumber Daya Manusia dan Produktivitas Kerja" Bandung: Mandar Maju.

Undang-Undang Republik Indonesia No. 2 tahun 1989 tentang Sistem Pendidikan Nasional

Umar. 2000 Manaajemen Sumber Daya Manusia untuk Bisnis yang Kompetitif, Yogyakarta: Gajah Mada University Press. 